\title{
Discourse analysis of blogs: Analyzing language to maximize the value of consumption-oriented blogs as data source
}

\author{
${ }^{1}$ Carmela Bosangit, ${ }^{2}$ Scott McCabe and ${ }^{2}$ Sally Hibbert \\ ${ }^{1}$ School of Management, Swansea University, Swansea, UK \\ c.a.bosangit@swansea.ac.uk \\ ${ }^{2}$ Nottingham University Business School, University of Nottingham, Nottingham, \\ UK \\ (scott.mccabe@nottingham.ac.uk; sally.hibbert@nottingham.ac.uk)
}

\begin{abstract}
The value of blogs to consumer research has been established; however, its full potential is still to be realized as empirical analyses into their use have been dominated by quantitative studies. There is a fundamental research gap in the range of methods adopted by researchers which has limited blogs as a source of valuable insights. This paper asserts the importance of language and the rhetorical functions of blogs as social interaction contexts where meanings are created and channeled; thus, offering a route to develop better understandings of authors and their narratives. Using discourse analysis to examine blogs, the paper demonstrates how a focus on language can provide rich insights to understand consumption experiences. Discourses of travel that emerged from the analysis were presented and theoretical and practical implications were outlined.
\end{abstract}

Keywords: Blogs, Discourse Analysis, Consumer Narratives, Travel Stories

\section{Introduction}

Extant literature on consumption-oriented blogs has provided evidence on how blogging has empowered consumers to self-publish their experiences and marketers and researchers have recognized the opportunities for these naturally occurring data as a data source (See work of Lu \& Stepchenkova, 2015; a systematic review of usergenerated content applications in tourism and hospitality research [1]). Consumption oriented blogs are valuable to marketers because they are accounts of products and experiences that relate to consumers' lives and which allow them to internalize the symbolic meanings embedded in their experiences [2]. Although there is an increase in empirical work demonstrating the potential of blogs in marketing these are dominantly quantitative in nature. This has also been observed in existing literature on 
travel blogs. According to Banyai and Havitz (2012), content of travel blogs has commonly been reduced to statistical data and mere categories [3]. There are only a few studies on travel blogs using qualitative research methods such as narrative analysis, qualitative content analysis and discourse analysis [4, 5, 6, 7, 8]. Most empirical work mining travel blog content has been quantitative content analysis focused on specific destinations and extracting common themes related to destination image, tourist evaluation of the destination and actual tourist behavior [7]. On the other hand, netnography has been used to analyze consumption-oriented blogs in different consumption contexts $[2,9]$. One reason for the use of more quantitative techniques could be the huge amount of data that is available, and the fact that the data is in a digital format at source. Thus researchers may feel tempted into more technologically driven methods of data cleaning, manipulation and analysis. Yet we argue that much valuable interpretive analysis is omitted from such a myopic approach to these rich, naturally occurring datasets.

Using quantitative research methods limits the potentials of blogs for understanding the writers/narrators and how they reconstruct their consumption experiences. There is a missed opportunity because blogs are personal and deeply subjective in nature and represent fruitful opportunities for qualitative researchers because they offer investigators a publicly available conduit to backstage thoughts and feelings of others [10]. For example, using qualitative approach in analyzing blogs can provide insights to the processes by which events and activities are transformed into personally meaningful experiences [11], which cannot be captured using quantitative research methods. Bosangit, McCabe and Hibbert (2009) call for researchers to explore other frameworks that are appropriate to maximizing the use of blogs in understanding rapid and continuously changing consumption experiences such as tourism [7]. Banyai and Havitz (2012), suggest that a realist evaluation approach could maximize the potential of travel blogs by using qualitative techniques alongside quantitative methods [3].

Blogs represent a vast, diverse and idiosyncratic range of content which presents challenges for qualitative researchers. There are some useful guides to using qualitative approaches to blog data collection and analysis [12, 13, 14]. However, researchers and marketers may need more guidance and persuasion to adopt qualitative approaches. There is scant empirical work using qualitative techniques for the analysis of blogs both in the general field of marketing and tourism marketing. This paper therefore contributes to this research gap by illustrating how discourse analysis can be used to understand consumption experiences. Focusing on the language used by bloggers, the discourse analysis aims to address the following research questions: a. what type of stories are told by bloggers? and b. what are embedded in these stories that provide insights to consumption experiences?

Theoretically, this paper contributes to works highlighting how stories which are also embedded in blogs are fundamental to the conceptualization of consumption experiences, particularly tourist experiences $[15,16,22]$. For practical implications, mar- 
keters can use blogs to understand the non-visible and rarely stated elements in experiences (i.e. hedonic and subjective dimensions of experience) $[11,17]$ and provide insights to the development and design of marketing communication strategies. As the main purpose of this paper is to demonstrate the potentials of using qualitative approach in examining blogs as a data source, the next section focuses on the process of discourse analysis of travel blogs.

\section{Discourse Analysis of Blogs}

Discourse analysis (DA) is appropriate for studying blogs because it is concerned with the way texts are constructed, the functions they serve in different contexts and the contractions that run through them [18]. There are several different approaches to social constructionist discourse analysis such as discourse theory, Foucauldian perspectives, critical discourse analysis and discursive psychology (see Jorgensen and Philipps, 2002 for the differences among these approaches) [19]. This paper draws on discursive psychology (DP) as it will allow an examination of how blogs are constructed [20,21] and how texts are socially organized to achieve local actions such as identity management [22]. DP favors the analysis of records of natural interaction or textual materials produced as part of life's activities rather than using experiments, surveys and interviews to generate research data, because of its emphasis on how both "reality" and "mind" are constructed by people conceptually, in language, in the course of their performance of practical tasks. Blogs are one form of this textual material.

In the tourism context, discourse analysis is a rarely used method. Jaworski and Pritchard (2005) had noted how discourse and communication scholars historically have little dialogue with scholars in tourism [23]. According to McCabe and Foster (2006: 195) [24], the work of Dann (1996) remains the cornerstone for researchers interested in socio-linguistic interpretation of discourses of tourism [25]. Compared to other popular methods for analyzing travel blogs such as content analysis and narrative analysis [8], DA can provide a deeper understanding of travel blogs beyond a mere listing of destination attributes. Willig (2008) described DA as a particular way of reading - reading for action orientation (what is the text doing?), rather than simply reading for meaning (what is this text saying) [24]. Potter and Wetherell (1987) confirmed that there is no mechanical procedure for producing findings from an archive of transcript [27, 28]. However, several discourse analysts have suggested guidelines for doing DA such as Potter and Wetherell's (1987) 10 stages in the analysis of discourse [27]; Billig's (1991) procedural guide for DA [29]; Wiggins and Potter's (2008) detailed and comprehensive guidance on the practicalities of DP research [30], and Antaki et al's (2003) evaluating DP research [31].

For this paper, Potter and Wetherell's (1987) 10 stages for a discursive psychological analysis was adopted [27] by the authors as this is appropriate for analyzing travel blogs as the data source of consumption experience. The stages include: 1) research 
questions; 2) sample selection 3) collection of records and documents; 4) interviews; 5) transcription; 6) coding; 7) analysis; 8) validation, 9) the report and 10) application. As travel blogs were used as the data source, and does not involved interview and transcription, stages 3, 4 and 5 were replaced by the authors with downloading of blogs for the analysis. These stages are grouped into three phases of the study: pre-discourse analysis, discourse analysis and post-discourse analysis. Figure 1 below illustrates these three stages in detail.

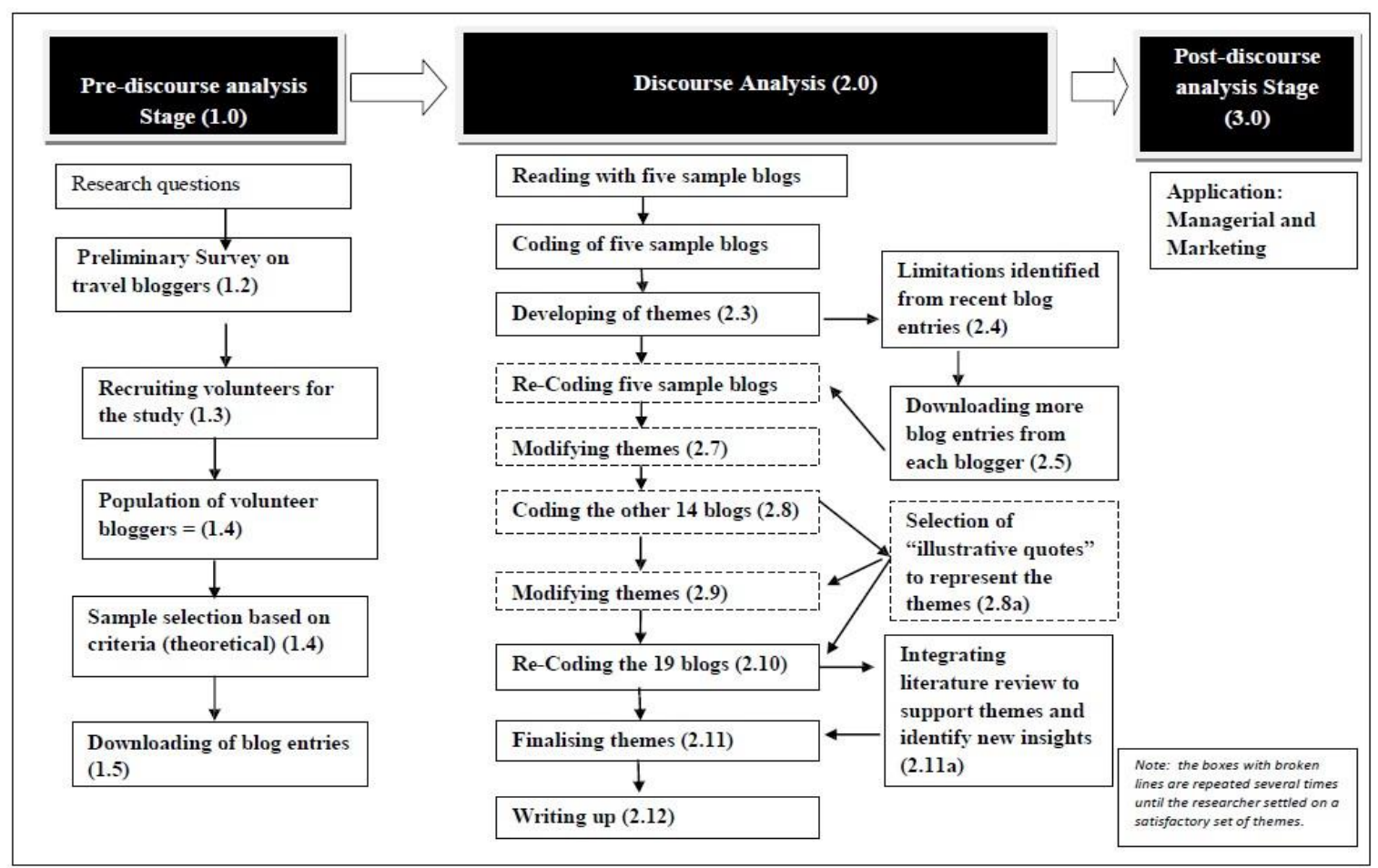

Figure 1. Discourse analysis process (developed by the authors)

The pre-discourse analysis involved the following: setting of the research objectives; a survey among travel bloggers as there was no available data on travel bloggers during the research period; and the identification of sample travel blogs to be used for the discourse analysis. The survey was conducted to gain an understanding of blogger's profiles, motivation and practices which facilitated the identification of sample of bloggers and blogs that would be appropriate for addressing the research questions. From the 1,214 respondents of the survey, volunteers for the discourse analysis were recruited. 19 travel bloggers met the following criteria set: bloggers have blogged about long-haul and multiple destination trips that are longer than three weeks; have 
written between 25 and 50 blogs; blogs should have more text than pictures and written in English. With their consent, blogs were downloaded for the next stage.

The second stage which formed the discourse analysis was comprised of reading and a reiterative process of coding to identify the themes from the data set. During the initial stages of coding five blogs (steps 2.2 and 2.5), important extracts were put into a matrix against each blogger to clearly show variability and consistency among these bloggers. However, as coding reached steps 2.8 and 2.10. NVivo, qualitative software, was used to deal with the huge amount of data and categorized it into five established themes. After coding the data into these themes, another round of coding produced a better selection of illustrative quotes which best represent a theme. This stage ended with the writing up of the findings which fed into the third stage; the post discourse stage where management and marketing implications were identified.

\section{Discourses of Travel}

\subsection{Stories of Risk and Challenges}

Stories of voluntary or unexpected risks are typical to of long-haul and multiple destination travelers' narrative identity and reflect self-development or self change $[32,33]$. Risk-taking behaviors are expected of tourists because they perceive being on holiday as a "license for thrill" [34]. Hence, there are many stories constructed as risky situations such as skydiving, rafting, bungee jumping, and trekking, and mountain climbing. There are also "tourist risk" which refers to possible misfortunes that might befall travelers in the process of travelling or at their destination [35]. These are in stories of long, dangerous bus rides, being scammed, and being attacked by an animal or being close to a dangerous animal.

The construct of challenge is less explored in the tourism literature on its own as it is always associated with risk, adventure and frontier travel [36]; however, the analysis revealed that challenges are not limited to those particular types of experience. Challenges are personal and come in various forms of physical and mental challenges or any form of activity and situation that test someone's capability of dealing with them. Common forms of challenges retold by bloggers to their readers are experiences of physical challenges; conquering a specific fear (e.g. snorkeling, heights) and challenging practices and norms of a long-haul and multiple destination traveler. Below is an example of an account where the blogger highlighted the danger, the skills required and described the experience as an achievement.

"Well, today we were risking life and limb on what has been dubbed ... 'the most dangerous road in the world'...It was highly exhilarating and great fun and with the ability to go as fast or as slow as you wanted, it meant that you could squeeze as much or as little adrenaline out of you as you wished. One or two of our group came off their bikes gathering some flesh wounds to add to their travelling tales but most 
came off unscathed. Over the last few hours we had / travelled about $60 \mathrm{~km}$ and descended by over $3000 \mathrm{~m}$ in altitude,... we had also cheated death on the World's most dangerous road, something to be proud (and relieved) about! What an excellent experience!" (Chrissie and Mark)

Bloggers also shared accounts of failures of achieving their set goals, and in these stories, self-presentation technique such as self-handicapping were used [37]; where the blogger produces obstacles to success with the purpose of preventing observers from making dispositional references about one's failure. Outcomes can either be positive or negative but what was important was to challenge one's limit as it is important for an evolving self [38]. These stories are integrated in the life story of the blogger and contribute to their identity work.

\subsection{Accounts of Learning and Reflections}

The analysis showed bloggers sharing what they learn about the destination (the place and the people) and how they personalized their experience by integrating their reflections on what they have seen within their previous experience or even existing knowledge prior to the visit. This confirm that learning experiences are more enjoyable when they can take their own personal meaning [39]. How they construct these stories may also indicate an aspect of their identity as a "learner" or their interests. This extract from a blogger's account on Nazca lines is an example of how he personalized his experience.

"There are a whole host of theories as to why these lines in the desert were created approximately 2000 years ago...A German mathematician has spent her life dedicated to the cause and theorised that the lines are an astronomical calendar mapped out by complex mathematics, another theory is that they map the routes to water, which in the harsh desert is a valuable commodity. There are of course the usual extraterrestrial landing site theories but the most widely accepted is that they're connected to ritual walkways from a religious based cult. I have my own theory of course... I believe there is someone in the afterlife looking down and laughing at us. "Look at all those crazy Gringos's paying good money to ogle something some friends and I scratched in the dirt when we were bored". Whatever reasons the lines came to be, I was sure they'd be pretty spectacular" (Michael)

Bloggers differ in their use of linguistic techniques, style of writing, use of emotional words and integrating their opinions with facts and stories about the places. They filter and expand on their stories as they want to share to their readers. Travel blogs indeed provide a good access to the learning and reflections of the travelers which are less explored in the tourist studies literature. Pearce (2005) posited that what tourists learn is seen to have limited commercial interest [40]. However, the analysis has shown how bloggers value this aspect of their experiences as these stories 
enhance their social status hoping to get recognition from their readers for "discovering" or experiencing the place before them which gives them some authority to talk about it because they have been there like any frontier travelers [36].

\subsection{Accounts of Novelty and Differences}

Novelty and strangeness are essential elements in the tourism experience [41]. These concepts are based on the perception of what the individual knows or is familiar with. There are stories of novelty in activities they engaged in enhanced by its location and with whom they engaged it with. The stories that bloggers tell of their encounters with the locals is equivalent to what Jasinki (2001) call as "rhetorics of othering" [42]. The extract below shows a blogger reaction to what she has witnessed, a memorable experience to share with her readers.

"I was saddened to witness several cremations as well as babies' body being thrown directly in the river. Such intimate rituals of life and death take place in public which is a shock to me but merely the crossing between the physical and spiritual world in the Hindu culture" (Meltem)

Other examples of these stories include accounts of playing pool with a lady boy in a Vietnamese bar and playing football with the Indians in the Andes in Cusco, Peru. Some bloggers pay closer attention to how the locals live which facilitate their appreciation of their home culture and enhances their identity as they use the differences to know the self. The construct of novelty is very vague but personal and subjective, it can cover anything that a blogger writes about and points out to their readers as something that is strange, unique and bizarre or interesting and has produced emotions of surprise, shock, amazement. The analysis confirm that the element of novelty is still crucial in creating memorable experiences [43, 44].

\subsection{Accounts of self-expansion}

Social interaction with other fellow tourists is both an integral and functional aspect of backpacking [45]. But the analysis reveals that there is more to the social interaction of travelers, these interactions have helped them with their self-expansion. Self-expansion is achieved when an individual enters into a close relationship with another person, in which they include the other in their concept of self in the sense that they feel as if the other's perspectives, resources and identities are to some extent similar to their own [46:218). Interaction with fellow tourists gave bloggers specific resources such as knowledge, status and a sense of belonging to a community by identifying themselves with these people. Knowledge or the sharing of information is the most common resource gained from other travelers which ranges from prices of accommodation, how to get to certain place, best accommodation and additional tips. These practices are common features of backpacking [33, 48]; and are considered ways of gaining road status [50] which enhances their identity as a backpacker or traveler. 
Some bloggers talk about other travelers they meet in their travels and associate themselves to them. For example, a blogger described her friends as "great minded travelers" and sharing the same passion (traveling) which enhances her identity to her readers. Clearly identifying themselves with people who they think are exceptional is also seen in this account:

"He was here in Vietnam flying helicopters ... he got shot in the leg by a machine gun ...He has spent a huge amount of his time back in Vietnam and has helped local people achieve the most extra ordinary things that they may never have even dreamt of doing if they had not met him. Luckily for me he was here, this time he was busy learning the Viet language. Kent, Stu and I spent hours chatting, it was so good meeting someone like him and I soon realised with our conversations that us travel bloggers really experience and see within the more finer details of this big wide world, what with all our endless questions, unique experiences, trusty cameras and note books always at hand" (Claire)

In this extract the blogger was able to present an aspect of herself as a travel blogger and formalize her belonging to that group. In the tourism literature, this self-expansion model is not explored and these stories signal that this concept needs to be recognized as one of the benefits of travelling.

\subsection{Stories of escape}

This is the least dominant theme; however, it represents an important part of tourist experience as it covers moments when bloggers take a break from travelling. According to Cohen and Taylor (1992) escape depends on a reality that individuals escape from [49]. Hence, these stories of escape are unique from the construct of escape established in the literature which is usually an escape from boredom or everyday routine. Bloggers' reality over the period they have been traveling have changed as their everyday life is now filled with work of traveling, making travel their "occupational career".

Escape comes in various forms. First, it can take the form of rest and relaxation or at least a less active day for some bloggers. Stories of escape are usually short, with some bloggers even saying there is not much to post in the blog because they "just chilled out for the day", email people, chat or even did the laundry. Second, the beach paradise as an escape has been a dominant feature in their stories. Despite travelers being in different places with varied travel motivations, the beach is one of the places, they consumed commonly. Third, sleep is one of the most mentioned words albeit in varying contexts such as letting their bodies recuperate from any strain they subjected them to, in preparation for a strenuous activity or simply because they want a lazy morning and to get up late. Below is a short extract from a blogger admitting the need to rest after travel.

“...the past 3 months of travelling was starting to catch up with me... so I would take time out relaxing in my room reading, watching tv and sleeping”(Meltem) 
Despite its importance to travelers, sleep in tourism literature has not been explored. In fact, only the work of Valtonen and Veijola (2011) recognized the theoretical and industry-related insights of the tourist experience of the embodied state and practice of sleeping [50]. They emphasized that sleep has always been seen as an indicator of development and success in tourism in terms of overnight stays; but sleep itself has been left untouched.

\section{Conclusion}

This study has demonstrated how discourse analysis of blogs as naturally occurring data can provide insights on consumption experiences that may prove elusive when applying more commonly used-researcher led approaches such as direct interviewing techniques [11]. The discourse analysis provided more in-depth understanding of the subjective reality of bloggers and the meanings they have assigned to their travel experiences [8]. Focusing on the language used by bloggers, five dominant types of travel stories emerged through the discourse analysis of blogs written by 19 British travel bloggers. These themes reflect common types of stories which constitute a tourist experience that bloggers felt worth sharing with their readers. Embedded within these stories are memorable experiences of the bloggers, which also provide insights on their selfpresentation strategies and techniques used as well as the value and meaning of these travel experiences to them.

This research contributes to the literature on conceptualizing tourist experiences as it confirms the role of blogs in empowering travelers to share their stories to their readers. In terms of marketing implications, this research has provided empirical evidence on how blogs can reveal core consumption experiences as remembered and reconstructed by the consumers. Blogs have provided their readers access to their feelings, thought processes and reflections. Further, the research confirms that travel experience remains to be used for identity construction [21, 29, 31]. Therefore, marketers in their formulation of a destination brand should pay particular attention in offering experiences that will give tourists opportunities to present or enhance their identities through the stories they tell.

\section{$5 \quad$ References}

1. Lu, W., \& Stepchenkova, S. (2015). User-generated content as a research mode in tourism and hospitality applications: Topics, methods, and software. Journal of Hospitality Marketing \& Management, 24(2), 119-154.

2. Zhao, X., \& Belk, R. W. (2007). Live from shopping malls: Blogs and Chinese consumer desire. Advances in Consumer Research, 34, 131.

3. Banyai, M., \& Havitz, M. E. (2013). Analyzing travel blogs using a realist evaluation approach. Journal of Hospitality Marketing \& Management, 22(2), 229-241. 
4. Tussyadiah, I. P., \& Fesenmaier, D. R. (2008). Marketing Places Through First_Person Stories - an Analysis of Pennsylvania Roadtripper Blog. Journal of Travel \& Tourism Marketing, 25(3-4), 299-311.

5. Berger, I. E., \& Greenspan, I. (2008). High (on) technology: Producing tourist identities through technologized adventure. Journal of Sport \& Tourism,13(2), 89-114.

6. Bosangit, C. (2012). Understanding consumption experiences: a discourse analysis of travel blogs (Doctoral dissertation, University of Nottingham).

7. Bosangit, C., McCabe, S., \& Hibbert, S. (2009). What is told in travel blogs? Exploring travel blogs for consumer narrative analysis. Information and communication technologies in tourism 2009, 61-71.

8. Banyai, M., \& Glover, T. D. (2012). Evaluating research methods on travel blogs. Journal of Travel Research, 51(3), 267-277.

9. Kulmala, M., Mesiranta, N., \& Tuominen, P. (2013). Organic and amplified eWOM in consumer fashion blogs. Journal of fashion marketing and management, 17(1), 20-37.

10. Chenail, R. J. (2011). Ten steps for conceptualizing and conducting qualitative research studies in a pragmatically curious manner. The Qualitative Report, 16(6), 1713

11. Bosangit, C., Hibbert, S. and McCabe, S. (2015). "“If I was going to die I should at least be having fun": Travel blogs, meaning and tourist experience." Annals of Tourism Research 55, 1-14.

12. Wakeford, N., \& Cohen, K. (2008). Fieldnotes in public: using blogs for research. The Sage Handbook of Online Research Methods, 307-326.

13. Ward, R. (2006). Blogs and wikis A personal journey. Business Information Review, 23(4), 235-240.

14. Hookway, N. (2008). Entering the blogosphere': some strategies for using blogs in social research. Qualitative research, 8(1), 91-113.

15. McGregor, I. and Holmes (1999). How storytelling shapes memory and impressions of relationship events over time. Journal of Personality and Social Psychology, 76 (3), 403-419.

16. Moscardo. G. (2010). The shaping of tourist experience: The importance of stories and themes. In: M. Morgan, P. Lugosi, J.R.B. Ritchie (Eds), The tourism and leisure experience: Consumer and management perspectives, Channel View Publications, Bristol, pp. 3-26.

17. Carù, A and Cova, B. Small versus big stories in framing consumption experiences. Qualitative Market Research: An International Journal, 11(2), 166-176.

18. Parker, I. (2004). 5.19 Discourse Analysis. A companion to qualitative research, 308.

19. Jørgensen, M. W., \& Phillips, L. J. (2002). Discourse analysis as theory and method. Sage.

20. Potter, J. (1996). Discourse analysis and constructionist approaches: Theoretical background. British Psychological Society

21. Burr, V. (2015). Social constructionism. Routledge.

22. Ausgustinos, M and Every, D. (007). Contemporary racist discourse: taboos against racism and racist accusations. In: Watson,B. and Galloise, C.A. (eds). Language, Discoruse and Social Psychology, Hampshire: Palgrave MacMilla: 233-255.

23. Jaworski, A. and Pritchard, A. (2005) Discourse, communication and tourism, UK: Channel View Publications.

24. McCabe, S. and Foster, C. (2006) "The Role and Function of Narrative in Tourist Interaction", Journal of Tourism and Cultural Change, 4(3):194-215.

25. Dann, G. (1996) The language of tourism: A sociolinguistic perspective, Oxon: CAB International

26. Willig, C. (2008) Introducing qualitative research in psychology: Adventures in theory and method, 2nd edition, Berskshire: Open University Press. 
27. Potter, J., \& Wetherell, M. (1987). Discourse and social psychology: Beyond attitudes and behaviour. Sage.

28. Langdridge, D. and Hagger-Johnson, G. (2009) Introduction to research methods and data analysis in psychology, Essex: Pearson Education Limited.

29. Billig, M. (1991). Ideology and Opinions. London: Sage Publications.

30. Wiggins, S., \& Potter, J. (2008). Discursive psychology. The Sage handbook of qualitative research in psychology, 73-90.

31. Antaki, C., Billig, M., Edwards, D., \& Potter, J. (2003). Discourse analysis means doing analysis: A critique of six analytic shortcomings. Retrieved from: https://dspace.lboro.ac.uk/dspace-jspui/handle/2134/633

32. Desforges, L. (2000) "Travelling the world: identity and travel biography", Annals of Tourism Research, 27 (4):926-945.

33. Noy, C. (2004) "The Trip Really Changed Me: Backpackers' Narratives of SelfChange", .Annals of Tourism Research 31(1): 78-102.

34. Wickens, E. (1997) "Licensed for Thrill: Risk Taking and Tourism", In Clift, S. and Gabowski, P. (eds) Tourism and Health. London: Pinter

35. Tsaur, S., Tzeng, G. And Wang,K. (1997) "Evaluating tourist risks from fuzzy perspectives", Annals of Tourism Research, 24 (4): 796-812.

36. Laing, J. And Grouch, G. (2005) "Extraordinary journeys: An exploratory cross-cultural study of tourists on the frontier", Journal of Vacation Marketing, 11(3): 209-223.

37. Berglas, S. and Jones, E. E. (1978) "Drag choice as a self-handicapping strategy response to noncontingent success", Joumal cf Personality and Social Psychology, 36:405-417.

38. Cziksenthmihalyi, M. (1993). The evolving self. New York: HarperCollins Danziger, P. (2006). Shopping: why we love it and how retailers can create the ultimate customer experience. Chicago: Kaplan Publishing.

39. Falk, J. and Dierking, L. (2000) Learning from Museums: Visitor Experiences and the Making of Meaning. Walnut Creek, CA: AltaMira Press.

40. Pearce, P. (2005) Tourist behaviour: Themes and Conceptual Schemes, Clevedon: Channel View Publications.

41. Cohen, E. (1972) "Towards a sociology of international tourism”, Social Research, 39 (1): $164-182$.

42. Jasinski J (2001) Sourcebook on Rhetoric: Key Concepts in Contemporary Rhetorical Studies. Thousand Oaks, CA: SAGE.

43. Poulsson, S. and Kale, S. (2004) "The experience economy and commercial experiences", The Marketing Review, 4: 267-277.

44. Toffler, A. (1970) Future shock, New York: Bantam Books.

45. Murphy, L. (2001) "Exploring social interactions of backpackers", Annals of Tourism Research, 28 (1): 50-67.

46. McLaughlin-Volpe, T.(2008) "Understanding stigma from the perspective of the selfexpansion model”, In Levin, S. and van Laar, C. (eds) Stigma and Group Inequality: Social Psycholgical Perspectives, New Jersey: Lawrence Erlbaum Associates, Inc.

47. Riley, P. (1988) "Road Culture of International Long-Term Budget Traveler", Annals of Tourism Research, 15(3): 313-328.

48. Sorensen, A. (2003) "Backpacker Ethnography", Annals of Tourism Research, 30 (4): 847-867.

49. Cohen,S. and Taylor, L. (1993) Escape attempts: the theory and practice of resistance to everyday life, London: Routledge.

50. Valtonen, A. and Veijola, S. (2011) "Sleep in tourism", Annals of Tourism Research, 28(1): 175-192. 